\title{
SISTEM INFORMASI GEOGRAFIS (SIG) ANALISIS DAN PERSEBARAN SEKOLAH MENENGAH ATAS (SMA) DI KOTA GORONTALO BERBASIS WEB
}

\author{
Budiyanto Ahaliki \\ Teknik Informatika \\ Politeknik Gorontalo \\ Bone Bolango, Gorontalo, Indonesia \\ Email : Budiyanto_ahaliki@poligon.ac.id
}

\begin{abstract}
Sistem Informasi Geografis (SIG) adalah Teknologi informasi modern yang digunakan untuk melakukan analisis peta dan mengintegrasi informasi, sehingga mudah dalam pengambilan keputusan. SIG pada penelitian ini digunakan dalam memetakan sebaran Sekolah Menengah Atas (SMA) di Kota Gorontalo yang tersebar di 9 Kecamatan yaitu Kecamatan Kota Timur, Kecamatan Kota Tengah, Kecamatan Kota Barat, Kecamatan Kota Utara, Kecamatan Kota Selatan, Kecamatan Sipatana, Kecamatan Dumbo Raya, Kecamatan Hulonthalangi, dan Kecamatan Dungingi.
\end{abstract}

Tujuan SIG ini adalah untuk mengetahui informasi akan letak persebaran SMA dan analisis informasi jumlah Guru dan siswa, sehingga dapat membantu pemerintah dalam pengembilan kebijakan akan peningkatan mutu pendidikan SMA di Kota Gorontalo. Manfaat dari SIG adalah membantu pemerintah dan pihak-pihak yang berkepentingan dapat memperoleh informasi berupa data alamat sekolah serta jumlah siswa dan guru pertahun. Metode pengumpulan data yang digunakan adalah metode dokumentasi dan observasi. Data yang dikumpulkan kemudian dianalisis dengan metode deskriptif.

Pembuatan Peta SIG berbasis WEB ini menggunakan Aplikasi Arcgis 10.2 sebagai digitasi peta dan frameworknya menggunakan pmapper sebagai pengolahan upload hasil peta digitasi kedalam WEB. Untuk pengolahan databasenya menggunakan Postgresql yang merupakan database yang mampu mengolah data spatial . Hasil dari analisis persebaran ini adalah berupa peta WEB SIG Persebaran SMA.

Kata kunci : Sistem Informasi Geografis (SIG), Persebaran, Sekolah Menengah Atas (SMA)

\section{PENDAHULUAN}

Kota Gorontalo adalah ibukota dari Provinsi Gorontalo yang memilki visi untuk menjadi Smart City. Misi yang dijalankan Kota Gorontalo salah satunya adalah Grand Strategy pemerintah dalam membangun infrastruktur perkotaan yang handal. Berbagai macam perencanaan dan pembangunan yang dilakukan oleh pemerintah untuk mewujudkan misi Kota Gorontalo yaitu Smart City. Perencanaan dan pembangunan Kota Gorontalo dalam mewujudkan visi dan misi terus dikembangkan, salah satunya adalah memfasilitasi sarana pendidikan Sekolah Menengah Atas (SMA) yang dibutuhkan oleh masyarakat.

Pemerintah Kota Gorontalo dalam hal ini sudah cukup peka terhadap sarana pendidikan yang memadai, dimana jumlah sekolah SMA baik negeri maupun swasta yang tersebar di wilayah Kota Gorontalo sebanyak 18 unit dengan jumlah siswa 3.845. (BPS Kota Gorontalo, 2015) . Banyaknya persebaran SMA di Kota Gorontalo membuat pemerintah kesulitan dalam mengontrol perkembangan dan kemajuan mutu pendidikan SMA di Kota Gorontalo.

Permasalahan tersebut di atas disebabkan karena informasi yang diperoleh pemerintah belum cukup dan kurangnya media informasi yang dapat menyajikan informasi sebaran sekolah SMA di Kota Gorontalo, sehingga pemerintah daerah sulit mengontrol dan mengambil keputusan dalam meningkatkan layanan pendidikan sesuai dengan kebutuhan masyarakat. Maka untuk itu perlu adanya dibuat sistem informasi modern yang mampu memberikan informasi secara visualisasi akan persebaran SMA di Kota Gorontalo yaitu dengan menerapkan Sistem informasi Geografis (SIG) yang mampu menganalisis dan menginformasikan persebaran sarana pendidikan SMA.

\section{METODOLOGI}

\subsection{Waktu dan Objek Penelitian}

Penelitian ini akan dilaksanakan selama 5 (lima) bulan, tahun 2016 dengan Objek dalam penelitian ini adalah sarana pendidikan formal di Kota Gorontalo, yaitu : Sekolah Menengah Atas (SMA).

\subsection{Metode Penelitian}

Metode dalam penelitian ini menggunakan metode survei yaitu penyelidikan yang dilakukan untuk memperoleh data fakta mengenai persebaran sarana pendidikan SMA di Kota Gorontalo. Metode survei yang digunakan meliputi survei lapangan dan metode dokumentasi.

Survei lapangan menggunakan GPS (Global position System) untuk mendapatkan titik-titik koordinat disetiap objek yang diambil. Sementara itu survey lapangan digunakan juga untuk mencari data- data primer, dengan melakukan penelitian secara langsung di lapangan. Tujuannya untuk mengetahui 
letak persebaran sarana pendidikan SMA di Kota Gorontalo. Sedangkan metode dokumentasi sebagai bentuk data sekunder yang diperoleh dari badan atau instansi terkait.

\subsection{Alat dan Bahan Penelitian}

\subsubsection{Alat}

1. Perangkat Keras (Hardware)
a. Labtop Acer Aspire One 4935
b. Intel Core2 Duo T6400@2GHz
c. Memory $2 G B$
d. VGA $256 \mathrm{MB}$
e. Printer Canon MP2580
f. Hardisk $250 \mathrm{~GB}$
g. Mouse \& Keyboard Acer Optional

2. Perangkat Lunak (Software)
a. Windows 7 Ultimate 32-bit (6.1, Build 7600)
b. ArcGIS 10.2
c. Database Spatial PostgreSql

\subsubsection{Bahan}

1. Data statistik sekolah SMA berupa nama sekolah, alamat, data jumlah siswa dan guru.

2. Data titik koordinat masing-masing sekolah SMA. Peta Kota Gorontalo.

\section{HASIL DAN PEMBAHASAN}

Hasil analisis pemetaan persebaran sekolah menengah atas terdapat beberapa analisis yaitu analisa sebaran sekolah, analisa jumlah guru, analisa jumlah siswa dan analisa sarana prasarana sekolah. Berikut adalah administrasi Kota Gorontalo.

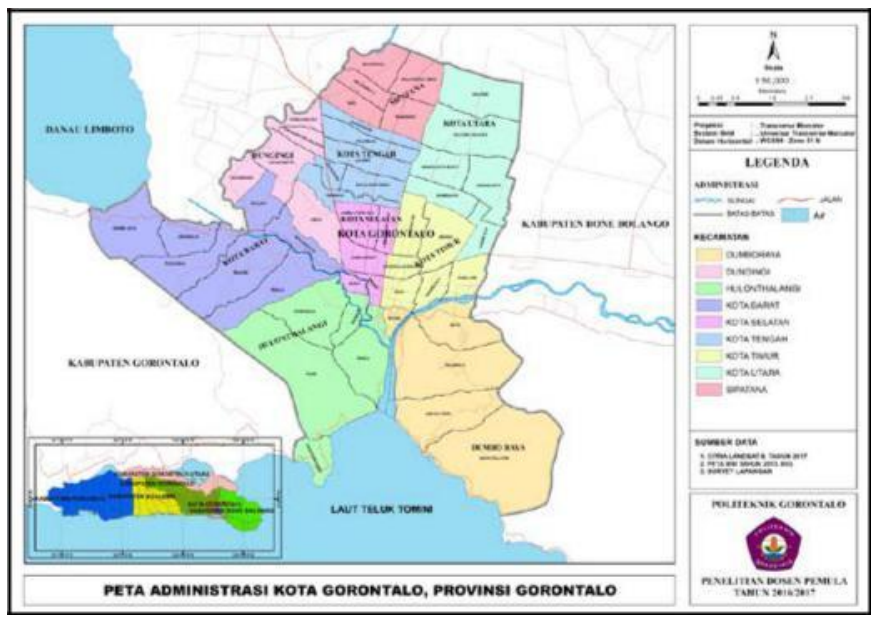

Gambar 3.1. Peta Administrasi Kota Gorontalo
Hasil yang dicapai dalam penelitian ini yaitu berdasarkan alur penelitian sebagai berikut :

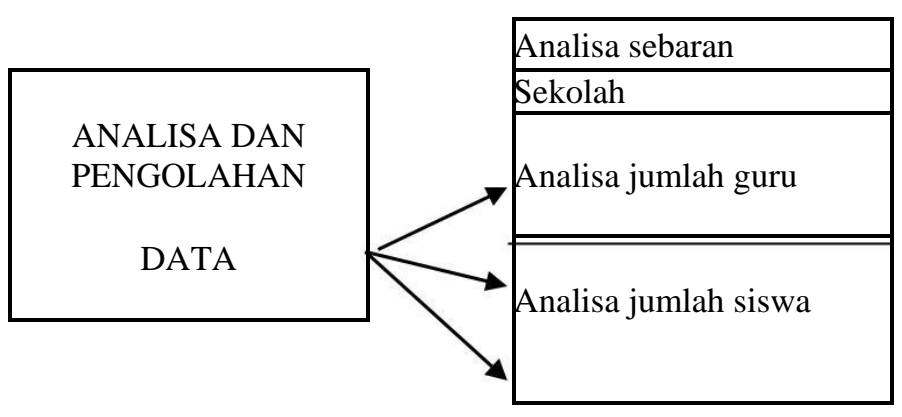

Hasil Analisis menggunakan Aplikasi ArcGIS 10.2 maka didapatkan Peta analisa sebaran sekolah, peta analisa jumlah guru, peta analisa jumlah siswa, peta analisa sarana prasarana sekolah dan peta administrasi Kota Gorontalo.

\subsection{Peta Analisa sebaran Sekolah}

Dari hasil data olahan primer dan sekunder terdapat 18 titik sekolah dimulai dari SMA, SMK dan MA baik swasta maupun negeri yang tersebar di beberapa titik kecamatan yang ada di Kota Gorontalo. Hasil analisa sebaran sekolah, ada beberapa kecamatan yang belum memiliki sekolah menengah atas seperti kecamatan Dumbo Raya, Kecamatan Hulonthalangi. Ada juga beberapa kecamatan yang memiliki lebih sekolah menengah atas seperti Kecamatan Kota Selatan, Kecamatan Kota Tengah dan Kecamatan Utara.

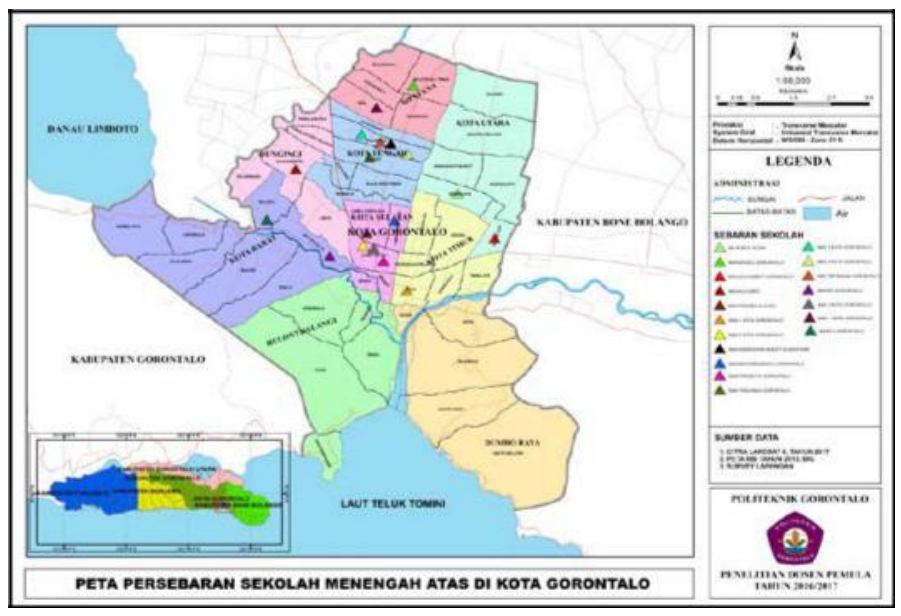

Gambar 3.2. Peta Persebaran Sekolah Menengah Atas di Kota Gorontalo

\subsection{Peta Sebaran Guru Sekolah}

Hasil analisa sebaran guru sekolah terdapat beberapa sekolah yang memiliki beban guru yang lebih seperti SMK 1, SMK 2, SMK 3, SMA 1, SMA 3 dan ada juga beberapa sekolah yang mengalami kekurangan guru mengajar seperti SMK BINA TARUNA, SMK TRIDHARMA, SMK TIRTAYASA DAN SMAS MUHAMMADIYAH. 

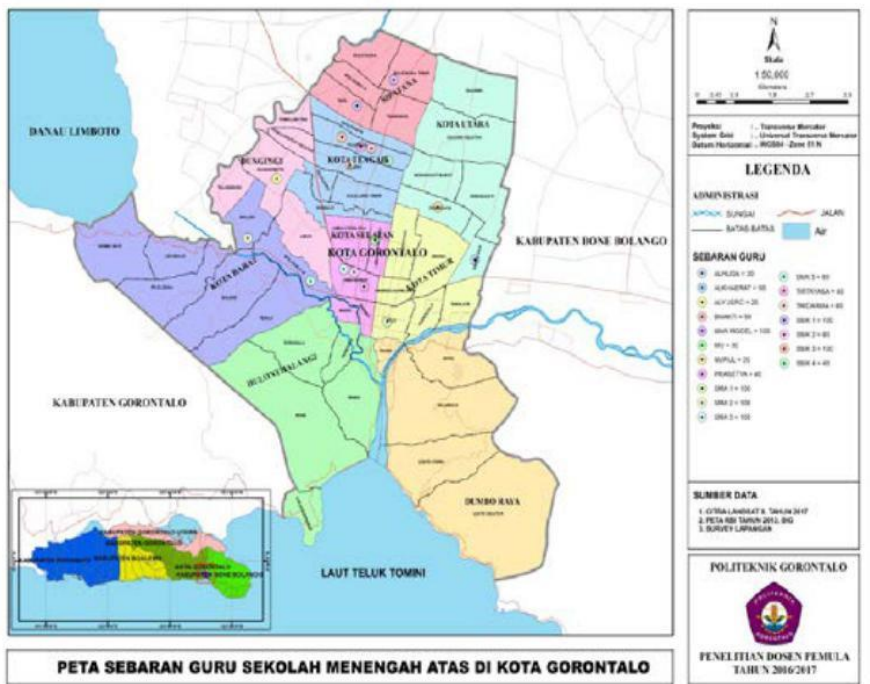

Gambar 3.3. Peta sebaran guru Sekolah Menengah Atas di Kota Gorontalo

Adapun Jumlah dari Sebaran Guru SMA, SMK di Kota Gorontalo dapat dilihat dalam table 1. berikut ini :

Tabel 1. Data sebaran Guru SMA, SMK di Kota Gorontalo.

\begin{tabular}{|c|c|c|c|c|c|}
\hline \multirow{2}{*}{$\begin{array}{l}N \\
0\end{array}$} & \multirow[b]{2}{*}{ Nama Sekolah } & \multicolumn{3}{|c|}{ Data Gurı } & \multirow{2}{*}{$\begin{array}{c}\text { Juml } \\
\text { ah }\end{array}$} \\
\hline & & Guru & $\begin{array}{c}\text { Tendi } \\
\mathrm{k}\end{array}$ & PTK & \\
\hline 1 & $\begin{array}{l}\text { SMK BINA TARUNA } \\
\text { GORONTALO }\end{array}$ & 9 & 1 & 10 & 20 \\
\hline 2 & SMKN 2 GORONTALO & 76 & 7 & 83 & 166 \\
\hline 3 & SMA PRASETYA GORONTALO & 19 & 3 & 22 & 44 \\
\hline 4 & SMAS MUHAMMADIYAH GTLO & 17 & 4 & 21 & 42 \\
\hline 5 & SMAN 3 GORONTALO & 68 & 6 & 74 & 148 \\
\hline 6 & SMKN 3 GORONTALO & 125 & 11 & 136 & 272 \\
\hline 7 & SMKN 4 GORONTALO & 39 & 8 & 47 & 94 \\
\hline 8 & SMK TRIDHARMA GORONTALO & 8 & 2 & 10 & 20 \\
\hline 9 & $\begin{array}{c}\text { SMKS KESEHATAN BHAKTI } \\
\text { NUSANTARA }\end{array}$ & 20 & 14 & 34 & 68 \\
\hline 10 & SMKS TIRTAYASA GORONTALO & 17 & 3 & 20 & 40 \\
\hline 11 & SMAN 2 GORONTALO & 49 & 6 & 55 & 110 \\
\hline 12 & SMKN 5 GORONTALO & 35 & 4 & 39 & 78 \\
\hline 13 & SMAN 5 GORONTALO & 15 & 6 & 21 & 42 \\
\hline 14 & SMAN I GORONTALO & 80 & 8 & 88 & 176 \\
\hline 15 & SMKN I GORONTALO & 151 & 13 & 164 & 328 \\
\hline 16 & SMAN 4 GORONTALO & 41 & 3 & 44 & 88 \\
\hline
\end{tabular}

\subsection{Peta Sebaran Siswa Sekolah}

Hasil analisa sebaran siswa sekolah terdapat beberapa jumlah siswa yang memiliki beban jumlah siswa lebih di beberapa sekolah seperti SMK 1, SMK 2, SMK 3, SMA 1, SMA 2, SMA 3 dan ada juga beberapa jumlah siswa yang mengalami kekurangan jumlah siswa seperti SMK BINA TARUNA, SMK TRIDHARMA dan SMAS MUHAMMADIYAH.
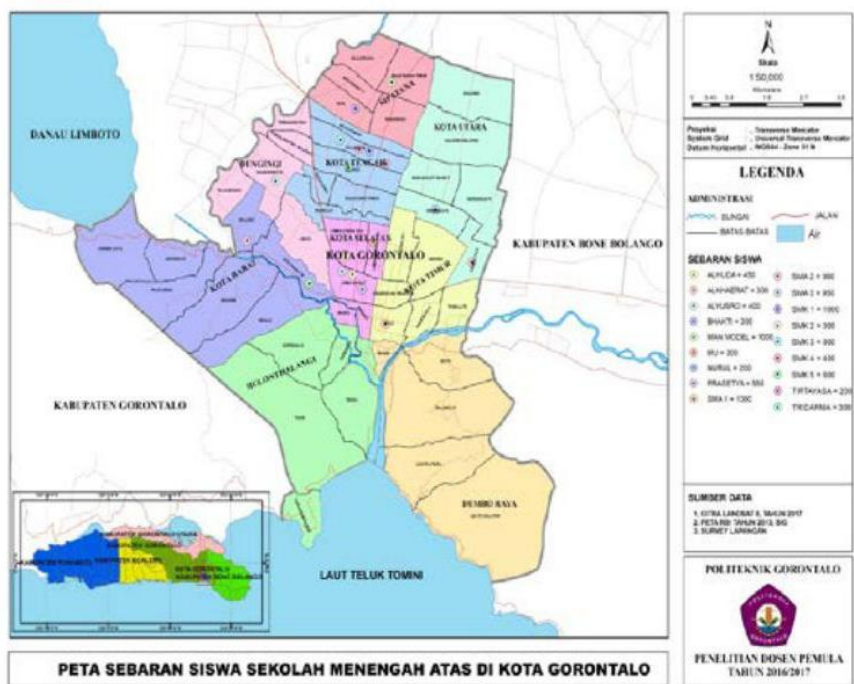

Gambar 3.4. Peta sebaran siswa Sekolah Menengah Atas di Kota Gorontalo

Adapun Jumlah dari Sebaran Siswa SMA, SMK di Kota Gorontalo dapat dilihat dalam table 3. berikut ini :

Tabel 2. Data sebaran Siswa SMA, SMK di Kota Gorontalo.

\begin{tabular}{|c|c|c|} 
No. & Nama Sekolah & $\begin{array}{c}\text { Peserta } \\
\text { Didik }\end{array}$ \\
\hline 1 & $\begin{array}{c}\text { SMK BINA TARUNA } \\
\text { GORONTALO }\end{array}$ & $\mathbf{4 6}$ \\
\hline 2 & SMKN 2 GORONTALO & $\mathbf{1 0 9 9}$ \\
\hline 3 & SMA PRASETYA GORONTALO & $\mathbf{2 2 8}$ \\
\hline 4 & SMAS MUHAMMADIYAH GTLO & $\mathbf{1 0 0}$ \\
\hline 5 & SMAN 3 GORONTALO & $\mathbf{1 3 1 4}$ \\
\hline 6 & SMKN 3 GORONTALO & $\mathbf{1 5 5 4}$ \\
\hline 7 & SMKN 4 GORONTALO & $\mathbf{4 1 0}$ \\
\hline 8 & SMK TRIHARMA GORONTALO & $\mathbf{4 8}$ \\
\hline 9 & SMKS KESEHATAN BHAKTI & $\mathbf{3 9 1}$ \\
\hline 10 & SMKS TIRTAYASA GORONTALO & $\mathbf{2 1 3}$ \\
\hline 11 & SMAN 2 GORONTALO & $\mathbf{9 7 8}$ \\
\hline 12 & SMKN 5 GORONTALO & $\mathbf{5 0 2}$ \\
\hline 13 & SMAN 5 GORONTALO & $\mathbf{1 9 1}$ \\
\hline 14 & SMAN 1 GORONTALO & $\mathbf{1 4 7 6}$ \\
\hline 15 & SMKN 1 GORONTALO & $\mathbf{1 9 7 5}$ \\
\hline 16 & SMAN 4 GORONTALO & $\mathbf{5 7 3}$ \\
\hline
\end{tabular}




\subsection{Peta Sarana Prasarana Sekolah}

Hasil analisa sarana prasarana sekolah terdapat beberapa jumlah sarana prasarana yang memiliki beban jumlah sarana prasarana lebih di beberapa sekolah seperti SMK 1 dan SMK 3, dan ada juga beberapa jumlah sarana prasarana yang mengalami kekurangan jumlah sarana prasarana seperti SMAN 5, SMK BINA TARUNA, SMK TRIDHARMA, SMK TIRTAYASA dan SMAS MUHAMMADIYAH.

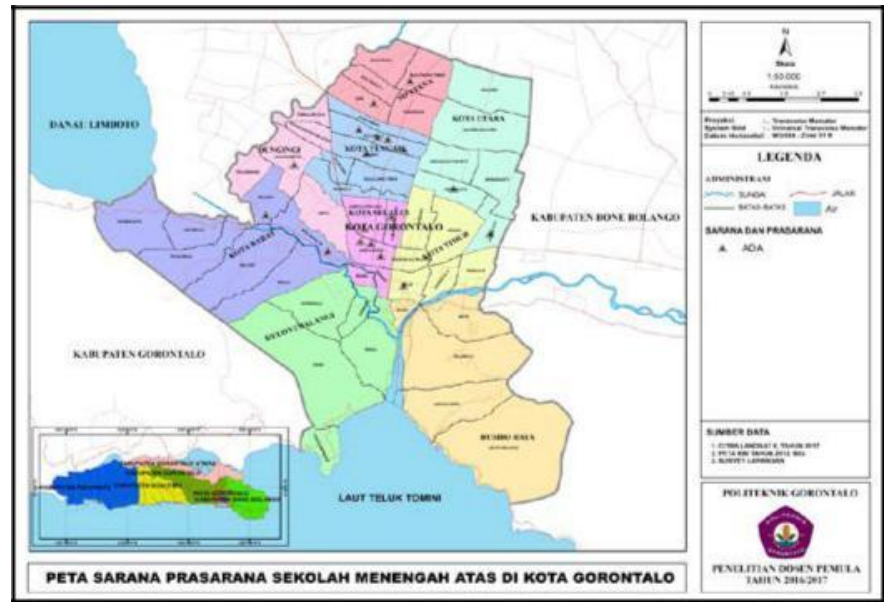

Gambar 3.5. Peta sebaran sarana prasaran Sekolah Menengah Atas di Kota Gorontalo

Adapun Jumlah dari Sebaran Sarana Prasarana SMA, SMK di Kota Gorontalo dapat dilihat dalam table 4. berikut ini :

Tabel 4. Data sebaran Sarana Prasarana SMA, SMK di Kota Gorontalo.

\begin{tabular}{|c|c|c|c|c|c|}
\hline \multirow[b]{2}{*}{$\begin{array}{l}\mathrm{N} \\
0\end{array}$} & \multirow[b]{2}{*}{ Nama Sekolalah } & \multicolumn{3}{|c|}{ Sarana Prasarana } & \multirow[b]{2}{*}{$\begin{array}{c}\text { Juml } \\
\text { ah }\end{array}$} \\
\hline & & $\begin{array}{l}\text { Ruang } \\
\text { Kelas }\end{array}$ & $\begin{array}{l}\text { Ruang } \\
\text { Lab. }\end{array}$ & $\begin{array}{c}\text { Peppu } \\
\text { staka } \\
\text { an }\end{array}$ & \\
\hline 1 & $\begin{array}{l}\text { SMIK BINA TARUNA } \\
\text { GORONAALO }\end{array}$ & 2 & 2 & 1 & 5 \\
\hline 2 & SMLN 2 GORONTALO & 24 & 3 & 1 & 28 \\
\hline 3 & SMA PRASETYA GORONTALO & 17 & 2 & 1 & 20 \\
\hline 4 & $\begin{array}{l}\text { SMMAS MUHAMGADIYYA } \\
\text { GILO }\end{array}$ & 7 & 3 & 1 & 11 \\
\hline 5 & SMAN 3 GORONTALO & 42 & 5 & 1 & 48 \\
\hline 6 & SMIN 3 GORONTALO & 51 & 3 & 1 & 55 \\
\hline 7 & SMIN 4 GORONTALO & 18 & 1 & 1 & 20 \\
\hline 8 & $\begin{array}{l}\text { SMIK TRDHARMAA } \\
\text { GORONTALO }\end{array}$ & 4 & 3 & 1 & 8 \\
\hline 9 & $\begin{array}{c}\text { SMIKS KRSERATAN BHAKTI } \\
\text { NUSANTARA }\end{array}$ & 13 & 1 & 1 & 15 \\
\hline $\begin{array}{l}1 \\
0\end{array}$ & $\begin{array}{c}\text { SMKS IIRTAYASA } \\
\text { GORONTALO }\end{array}$ & 6 & 1 & 1 & 8 \\
\hline $\begin{array}{l}1 \\
1\end{array}$ & SMAN 2 GORONTALO & 35 & 6 & 1 & 42 \\
\hline $\begin{array}{l}1 \\
2\end{array}$ & SMLN 5 GORONTALO & 19 & 1 & 1 & 21 \\
\hline $\begin{array}{l}1 \\
3 \\
\end{array}$ & SMAN 5 GORONTALO & 3 & 1 & 1 & 5 \\
\hline $\begin{array}{l}1 \\
4 \\
\end{array}$ & SMAN1 GORONTALO & 40 & 5 & 1 & 46 \\
\hline $\begin{array}{l}1 \\
5\end{array}$ & SMIN I GORONTALO & $n$ & 3 & 2 & 82 \\
\hline $\begin{array}{l}1 \\
6\end{array}$ & SMAN 4 GORONTALO & 20 & 4 & 1 & 25 \\
\hline
\end{tabular}

\subsection{Desain WEB GIS}

Perancangan sistem dalam WEB SIG menggunakan aplikasi pmapper. Aplikasi ini adalah aplikasi pengolah data web berupa .shp. berikut adalah tampilan hasil perancangan sistem menggunakan pmapper.

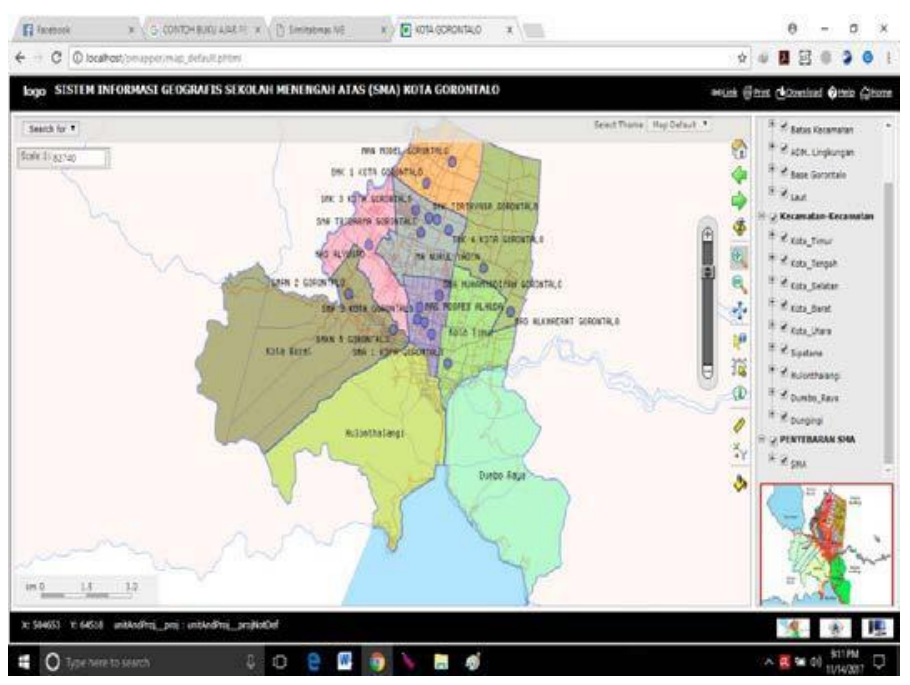

Gambar 3.6. Perancangan Desain WEB SIG sebaran sekolah

\section{KESIMPULAN}

Dari hasil analisa menggunakan data primer dan data sekunder mendapatkan hasil berupa analisa persebaran yang tidak merata di beberapa kecamatan yang ada di Kota Gorontalo, ada beberapa kecamatan yang lebih memiliki sekolah. Analisa jumlah guru yang tidak merata dibeberapa sekolah dan ada beberapa jumlah sekolah yang memiliki jumlah guru lebih dan ada yang kurang, begitu juga dengan jumlah siswa terdapat beberapa kelebihan jumlah siswa dibeberapa sekolah. Dilihat dari jumlah sarana prasarana sudah hamper merata dibeberapa jumlah sekolah yang ada di Kota Gorontalo.

\section{SARAN}

Berdasarkan penelitian yang telah dilakukan menggunakan metode yang diusulkan, ada beberapa hal yang diperhatikan dan perlu dikembangkan yakni :

1. Pemerataan persebaran sekolah menengah atas di beberapa kecamatan di Kota Gorontalo.

2. Pengambilan kebijakan oleh pemerintah dalam menangani beban jumlah guru dan siswa yeng lebih dibeberapa sekolah dan kekurangan jumlah guru di beberapa sekolah, serta jumlah murid yang kurang dan lebih dibeberapa sekolah. 


\section{DAFTAR PUSTAKA}

Alimah. 2012. Permasalahan Pendidikan di Indonesia.

(online),http://isaninside.files.wordpress.com/2008/06/perm asalahan_pendidikan_-ihsan.doc, di akses tanggal 07 April 2016).

Badan Pusat Statistik Kota Gorontalo, 2015. Kota

Gorontalo Dalam Angka. Gorontalo : Badan Pusat Statistik.

Peraturan Mentri Dalam Negeri. 2010. Tata Cara

Pengolahan Data Dan Informasi Perencanaan

Pembangunan Daerah.

Sumarno. 2009. Analisis Ketersediaan Sarana Dan

Prasarana Pendidikan Sekolah Dasar Di Kecamatan

Cepogo Kabupaten Boyolali.

Ulfiah, 2010. Sistem Informasi Geografi Pendidikan Kota Bogor Berbasis Web Dengan Menggunakan Quantum GIS. (online),

http://repository.gunadarma.ac.id:8080/bitstream/1234567

89/2946/1/Artikel_11104008.pdf, diaksestaanggal 20

Agustus 2017).

Prahasta, Eddy. 2009. Sistem Informasi Geografi. Bandung: Informatika

Prahasta, Eddy. 2011. Tutorial Destop ArcGis.

Bandung: Informatika.

Prahasta, Eddy. 2002. "Konsep-konsep Dasar Sistem

Informasi Geografi”. Bandung Informatika. 